\title{
PROSTATE CANCER;
}

EARLY CHANGES IN BONE METABOLISM AND SERUM SEX HORMONES IN ANDROGEN DEPRIVATION THERAPY

1. MBBS, MPhil, DIC, PhD

Department of Surgery and Cancer, Imperial College London, London, United Kingdom. Department of Biochemistry, Central Park Medical College, Lahore, Pakistan

2. MBBS, M.Phil

Department of Biochemistry, University of Health Sciences, Lahore, Pakistan.

Corresponding Address: Dr. Syed Imran Ali Shah Associate Professor \& Head Department of Biochemistry Central Park Medical College, 31-km Ferozpur Road, Lahore, Pakistan.

immishah@yahoo.com

Article received on: 08/12/2016

Accepted for publication: 15/02/2017

Received after proof reading: 06/04/2017

\section{Dr. Syed Imran Ali Shah', Dr. Mansoor Ghani}

ABSTRACT... Background: Androgen deprivation therapy (ADT) with luteinizing hormone releasing hormone agonists (LHRHa) is a major treatment modality for prostate cancer (PC), particularly advanced disease. LHRHa induced hypogonadism promotes bone loss, leading to osteoporosis and heightened fracture risk. Most previous studies on skeletal impact of LHRHa employed bone mineral density (BMD) testing. Serum bone-specific alkaline phosphatase (BSAP), an established bone biomarker, is reflective of changes in skeletal metabolism which precede BMD changes. In postmenopausal women, serum BSAP has been associated with fracture risk irrespective of BMD. Setting: Charing Cross Hospital, London, United Kingdom. Methods: We assessed early changes in serum BSAP levels of patients with non-metastatic PC $(n=9)$ undergoing LHRHa therapy. Serum testosterone and estradiol concentrations were also measured. Samples were taken at baseline before the start of treatment and three months afterward. Comparisons were made with blood samples taken at similar time points for agematched controls without PC $(n=9)$. Results: No significant difference in BSAP levels was seen between groups $(p=0.242)$. Testosterone and estradiol levels were significantly reduced following treatment $(p=0.000)$. No correlation was observed between serum BSAP and serum testosterone $(R=0.187, p=0.276)$ or serum estradiol $(R=0.055, p=0.75)$. Conclusions: Changes in serum BSAP levels may not be evident as early as 3 months following ADT with LHRHa. The study was limited by the small sample size and use of serum BSAP only which is one of the many bone markers. A larger study using multiple bone markers is warranted to determine early effects of LHRHa treatment on bone metabolism.

Key words: $\quad$ Prostate cancer, Sex hormones, Bone metabolism, Androgen deprivation therapy.

Article Citation: Shah SIA, Ghani M. Prostate cancer; early changes in bone metabolism and serum sex hormones in androgen deprivation therapy. Professional Med $\mathrm{J}$ 2017;24(4):534-538. DOI: 10.17957/TPMJ/17.3770

\section{INTRODUCTION}

Prostate cancer is a common male malignancy with an ever increasing global health-economic burden. ${ }^{1}$ The androgen-dependent nature of prostate cancer makes androgen deprivation therapy (ADT) a key treatment option particularly in patients with advanced disease. ${ }^{2}$ The iatrogenic reduction in serum testosterone and estradiol seen in prostate cancer (PC) patients following ADT with luteinizing hormone releasing hormone agonist (LHRHa) leads to reduction in bone mass, osteoporosis and heightened fracture risk. ${ }^{3,4}$ Several studies have looked at the impact of ADT on skeletal health and its detrimental effects are now widely recognized. Most of the studies done previously have employed bone mineral density (BMD) testing as a measure of bone loss. A decline in BMD after initiation of LHRHa treatment is suggestive of bone loss which predisposes to fractures. ${ }^{5-12}$

PC has a strong tendency toward bone metastases which disrupt skeletal homeostasis, resulting in elevated serum levels of biochemical markers of bone metabolism. ${ }^{13}$ These markers are associated with higher mortality and fracture rates in patients with metastatic disease. ${ }^{14}$ Alkaline phosphatase is one such marker which is derived from several sources including liver, bone, kidneys, spleen, intestines and placenta. ${ }^{15}$

Serum bone specificalkaline phosphatase (BSAP), a marker of osteoblast activity, can potentially be utilised as an early indicator of development of 
osteoporosis and associated fragility fractures. ${ }^{16}$ Changes in serum levels of BSAP precede changes in BMD. In postmenopausal women, serum BSAP is associated with fracture risk irrespective of BMD. ${ }^{17}$ This study was aimed at determining early changes in serum BSAP in patients with non-metastatic $\mathrm{PC}$ following initiation of ADT with LHRHa and to relate those changes to serum testosterone and oestradiol levels.

\section{METHODS}

The study was conducted at Charing Cross Hospital, London, United Kingdom. A longitudinal study design was employed. Patients with PC $(n=9)$ between the ages 50 to 75 years who were to begin ADT with LHRHa for either newly diagnosed advanced non-metastatic disease or as adjuvant or neoadjuvant to RT for localised disease provided blood samples for the study. Written informed consent was obtained and blood samples were taken at baseline before starting treatment and three months afterward. Comparisonswere made with blood samplestaken at similar time points from age-matched controls without PC $(n=9)$. Samples were centrifuged at $3000 \mathrm{rpm}$ for 10 minutes and separated serum was stored at $-80^{\circ} \mathrm{C}$ until assayed.

\section{Serum BSAP, testosterone and estradiol assays}

Serum samples were analysed at Imperial Clinical Chemistry Laboratory, Charing Cross Hospital for quantitative determination of BSAP, testosterone and oestradiol using commercially available kits. Serum BALP was measured using the Metra ${ }^{\circledR}$ BALP enzyme immunoassay (EIA) kit (Quidel ${ }^{\circledR}$ Corporation, San Diego, California, USA) (18). Serum testosterone and estradiol were measured by their respective ARCHITECT ${ }^{\circledR}$ assays (Abbott Laboratories, Abbott Park, Illinois, USA) using Chemiluminescent Microparticle Immunoassay (CMIA) technology with Chemiflex ${ }^{\mathrm{TM}}$ protocol (Abbott Laboratories, Abbott Park, Illinois, USA). The lowest detection limits of the assays were $0.45 \mathrm{nmol} / \mathrm{L}$ and $37 \mathrm{pmol} / \mathrm{L}$ for testosterone and estradiol respectively. ${ }^{19,20}$

\section{Statistical analysis}

The data were entered into and analysed using
SPSS version 22.0 (SPSS Inc, Chicago, Illinois, USA). Mean + S.E.M was calculated for normally distributed quantitative variables. One-way ANOVA was applied to observe group mean differences and post-hoc Tukey test was applied to observe which group means differ. Pearson's correlation was applied to observe correlation between BALP and serum sex hormone levels. A $p$-value of $<0.05$ was considered statistically significant.

\section{RESULTS}

The BSAP range of control group was 20.4-65 U/L (mean 32.01 U/L) at baseline and 24.0-65.2 U/L (mean $36.14 \mathrm{U} / \mathrm{L}$ ) at 3 months. The BSAP range of study group was 16.7-34.4 U/L (mean 26.15 $\mathrm{U} / \mathrm{L}$ ) at baseline and 5.7-45.6 U/L (mean 26.17 $\mathrm{U} / \mathrm{L}$ ) at 3 months after start of ADT. No significant difference in BSAP levels was observed between groups $(p=0.242)$ (Table-l). The testosterone range of control group was 9.19-27.70 nmol/L (mean $15.72 \mathrm{nmol} / \mathrm{L}$ ) at baseline and 9.41-22.55 $\mathrm{nmol} / \mathrm{L}$ (mean $14.85 \mathrm{nmol} / \mathrm{L}$ ) at 3 months. The testosterone range of study group was 9.31$21.40 \mathrm{nmol} / \mathrm{L}$ (mean $17.04 \mathrm{nmol} / \mathrm{L}$ ) at baseline and $0.45-1.42 \mathrm{nmol} / \mathrm{L}$ (mean $0.66 \mathrm{nmol} / \mathrm{L}$ ) at 3 months after start of ADT. Significant difference in testosterone levels was observed between groups $(p=0.000)$ (Table-l). The estradiol range of control group was 46-175 pmol/L (mean 102.78 $\mathrm{pmol} / \mathrm{L}$ ) at baseline and 56-131 pmol/L (mean $93.78 \mathrm{pmol} / \mathrm{L})$ at 3 months. The estradiol range of study group was 51-147 pmol/L (mean 90.56 $\mathrm{pmol} / \mathrm{L}$ ) at baseline. The mean value of estradiol in the study group at 3 months after start of ADT was $37 \mathrm{pmol} / \mathrm{L}$. Significant difference in estradiol levels was observed between groups $(p=0.000)$ (Table-I). Figure-1 depicts the group comparisons between the mean values of study parameters.

After applying post-hoc Tukey test, testosterone levels were significantly lower in the study group at 3 months than the study group at baseline as well as the control group at both assessments (baseline and 3 months) $(p=0.001)$. Estradiol levels of study group at 3 months assessment were significantly lower than estradiol levels of study group at baseline assessment and control group at both time points (baseline and 


\begin{tabular}{|c|c|c|c|c|c|}
\hline \multirow[t]{2}{*}{ Parameter } & \multicolumn{2}{|c|}{$\begin{array}{c}\text { Control group } n=9 \\
\text { Mean } \pm \text { S.E.M }\end{array}$} & \multicolumn{2}{|c|}{$\begin{array}{c}\text { Study group } n=9 \\
\text { Mean } \pm \text { S.E.M }\end{array}$} & \multirow[t]{2}{*}{ P-value } \\
\hline & Baseline & 3 months & Baseline & 3 months & \\
\hline BSAP (U/L) & $32.01 \pm 4.69$ & $36.14 \pm 4.94$ & $26.15 \pm 2.22$ & $26.17 \pm 3.62$ & 0.242 \\
\hline Testosterone (nmol/l) & $15.72 \pm 1.89$ & $14.85 \pm 2.05$ & $17.04 \pm 1.47$ & $0.66 \pm 0.14$ & $0.000 *$ \\
\hline Estradiol (pmol/l) & $102.78 \pm 13.41$ & $93.78 \pm 7.45$ & $90.56 \pm 9.35$ & $37.00 \pm 0.00$ & $0.000 *$ \\
\hline
\end{tabular}

3 months) $(p<0.001)$. No significant correlation was observed between serum BSAP and serum testosterone $(R=0.187, p=0.276)$ (Figure-2.) or serum estradiol $(R=0.055, p=0.75)$ (Figure-3).

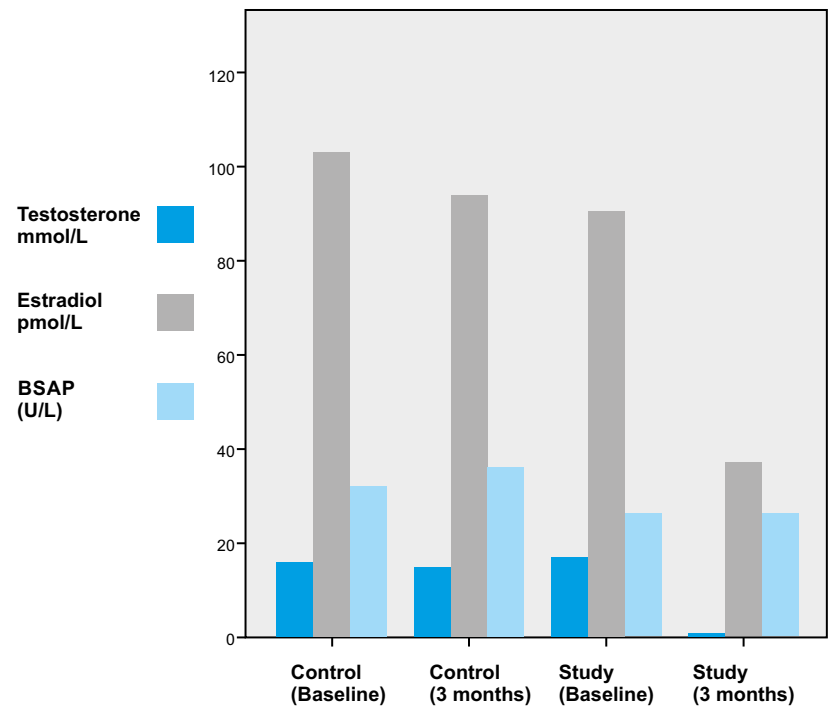

Figure-1. Mean BSAP, testosterone and estradiol levels in control and study groups at baseline and 3 months assessments

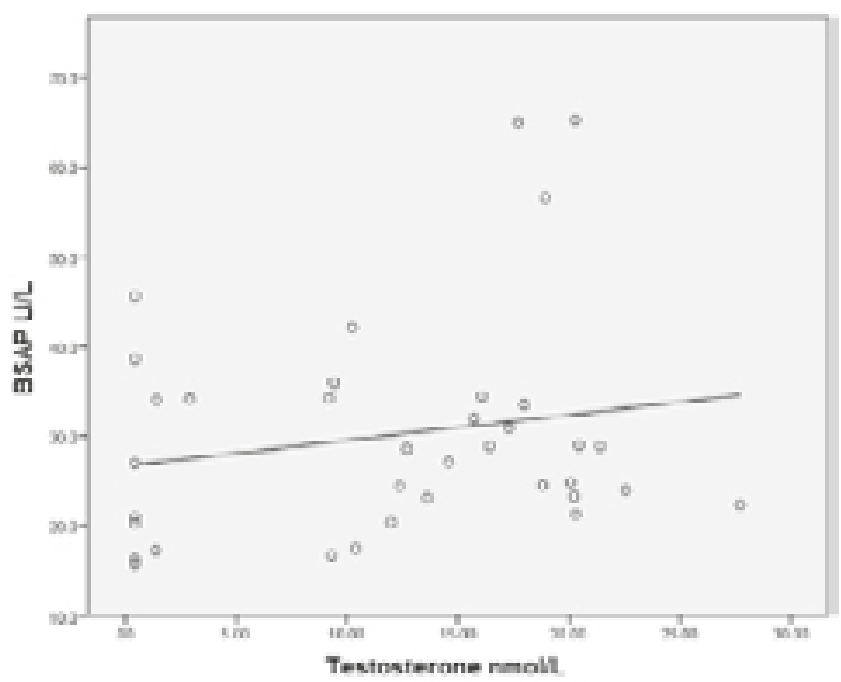

Figure-2. Scatter diagram of serum testosterone and BSAP levels

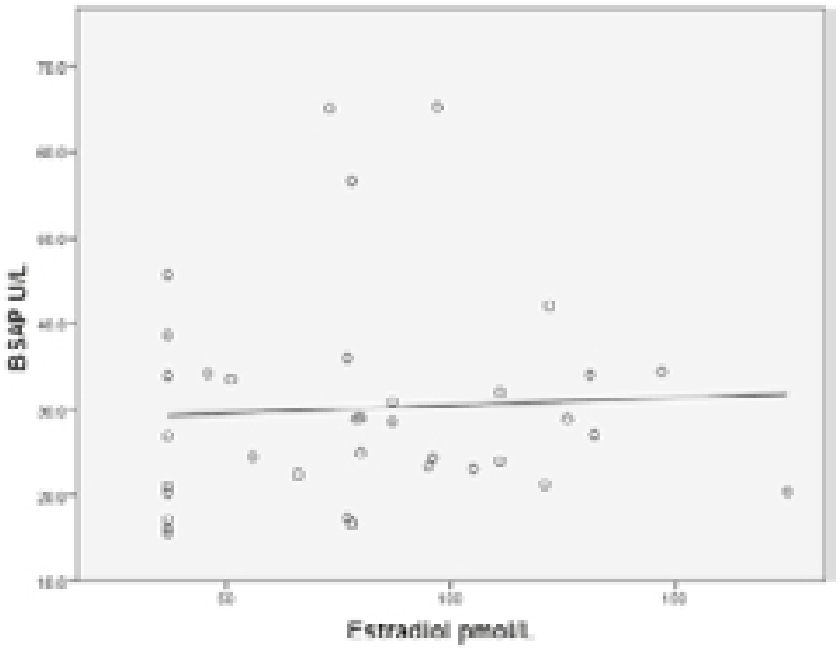

Figure 3. Scatter diagram of serum estradiol and BSAP levels

\section{DISCUSSION}

As both osteoblastic and osteolytic processes are involved in bone remodelling and turnover, metabolites of bone formation and resorption have been used to assess changes in skeletal homeostasis in several clinical contexts but such data are limited in the setting of ADT with LHRHa in PC. The present study looked at early changes in serum BSAP levels of patients undergoing ADT for PC. No change was observed in serum BSAP levels after 3 months of commencement of ADT (Table-I, Figure-1) although serum testosterone and estradiol levels were significantly reduced as compared to baseline concentration and control group $(p<0.001)$. No correlation was found between serum sex hormone and BALP levels (Figures-2,3). Unlike these findings, a previous study by Greenspan et al. showed a rise in bone turnover markers in men on ADT for PC. Serum BSAP, osteocalcin, procollagen type 1 aminoterminal propeptide and urinary $\mathrm{N}$-terminal telopeptide of type I collagen (NTX) were elevated in men receiving $\operatorname{ADT}(n=30)$ compared with non- 
ADT users $(n=72)$ and healthy controls $(n=43)$ after 12 months $(p<0.05)$. Urinary NTX was also elevated after 6 months in men on ADT compared with men not on ADT $(p<0.05) .{ }^{21}$ Greenspan et al. measured bone markers at 6 and 12 months from baseline whereas in the present study, BSAP was measured at 3 months from baseline. Further, the patients in the current study were ADT-naïve at baseline while patients included in the study by Greenspan et al. were already on ADT (mean duration of ADT at baseline was 2.9 +1.5 months).

In another study, Morote et al. showed increased serum BSAP levels in patients with non-metastatic $P C$ receiving combined androgen blockade $(n=35)$ over 5 year follow-up period. After 5 years, there was a $65 \%$ increase in mean serum BSAP concentration from the baseline pre-treatment values. The increase was highest $(32 \%$ from baseline) after the first year of commencement of treatment. ${ }^{22}$ Morote et al. measured BSAP levels annually for five years but changes in BALP levels immediately after castration were not determined.

The present results suggest that biochemical changes in skeletal metabolism as reflected by serum BSAP levels may not be evident as early as 3 months following ADT with LHRHa. However, this study is limited by the small sample size and comparison involving baseline and 3 month assessments. Another important limitation is the use of serum BALP measurements only which is one of the many markers of bone turnover. A larger prospective future study using serial assessments of multiple markers will help in determining the effects of acute reduction in sex hormones as a result of ADT on bone metabolism.

\section{Acknowledgements}

We are thankful to Drs. Richard Harvey and Alan Courtney (Imperial College NHS Trust) for their help with sample storage and analysis. We are also very grateful to Prof. Paul Abel for his contribution to the design and execution of the study.

Copyright@ 15 Feb, 2017.
REFERENCES

1. Siegel R, Naishadham D, Jemal A. Cancer statistics, 2012. CA: Cancer J Clin. 2012;62:10-29.

2. Thomas $B C$, Neal DE. Androgen deprivation treatment in prostate cancer. BMJ. 2013;346:e8555.

3. Vanderschueren D, Laurent MR, Claessens F, Gielen E, Lagerquist MK, Vandenput L, et al. Sex steroid actions in male bone. Endocr Rev. 2014;35:906-60.

4. Serpa Neto A, Tobias-Machado M, Esteves MA, Senra $\mathrm{MD}$, Wroclawski ML, Fonseca FL, et al. A systematic review and meta-analysis of bone metabolism in prostate adenocarcinoma. BMC Urol. 2010;10:9.

5. Morrison BF, Burrowes IE, Aiken WD, Mayhew RG, Fletcher HM, Reid ME. Bone mineral density in Jamaican men on androgen deprivation therapy for prostate cancer. Infect Agent Cancer. 2011;6:S7.

6. Malcolm JB, Derweesh IH, Kincade MC, DiBlasio CJ, Lamar KD, Wake RW, et al. Osteoporosis and fractures after androgen deprivation initiation for prostate cancer. Can J Urol. 2007;14:3551-9.

7. Morote J, Morin JP, Orsola A, Abascal JM, Salvador C, Trilla E, et al. Prevalence of osteoporosis during longterm androgen deprivation therapy in patients with prostate cancer. Urology. 2007;69:500-4.

8. Morgans AK, Fan $\mathrm{KH}$, Koyama T, Albertsen PC, Goodman M, Hamilton AS, et al. Bone complications among prostate cancer survivors: long-term followup from the prostate cancer outcomes study. Prostate Cancer Prostatic Dis. 2014;17: 338-42.

9. Van Hemelrijck $M$, Garmo $H$, Michaelsson $K$, Thorstenson A, Akre O, Stattin P, et al. Mortality following hip fracture in men with prostate cancer. PloS one. 2013;8:e74492.

10. Wu CT, Yang YH, Chen PC, Chen MF, Chen WC. Androgen deprivation increases the risk of fracture in prostate cancer patients: a population-based study in Chinese patients. Osteoporos Int. 2015;26:2281-90.

11. Shahinian VB, Kuo YF, Freeman JL, Goodwin JS. Risk of fracture after androgen deprivation for prostate cancer. New Eng J Med. 2005;352:154-64.

12. Shao $\mathrm{YH}$, Moore DF, Shih $\mathrm{W}$, Lin $\mathrm{Y}$, Jang TL, Lu-Yao GL. Fracture after androgen deprivation therapy among men with a high baseline risk of skeletal complications. BJU int. 2013; 111:745-52.

13. Kamiya N, Suzuki H, Endo T, Yano M, Naoi M, Nishimi D, et al. Clinical usefulness of bone markers in prostate cancer with bone metastasis. Int J Urol. ;19:968-79. 
14. Brown JE, Cook RJ, Major P, Lipton A, Saad F, Smith M, et al. Bone turnover markers as predictors of skeletal complications in prostate cancer, lung cancer, and other solid tumors. J Natl Cancer Inst. 2005;97:59-69.

15. Thomas SDC. Bone turnover markers. Aust Prescr. 2012;35:156-8.

16. Talwar SA, Aloia JF. Bone markers in osteoporosis. In: Griffing GT, editor. Medscape drugs and diseases 2014.

17. Garnero P, Sornay-Rendu E, Claustrat B, Delmas PD. Biochemical markers of bone turnover, endogenous hormones and the risk of fractures in postmenopausal women. J Bone Miner Res. 2000;15:1526-36.

18. Quidel-Corporation. An enzyme immunoassay for the quantitation of bone-specific alkaline phosphatase (BAP) in human serum. In: Corporation $Q$, editor. San
Diego, California, USA 2006. p. 1-13.

19. AIDD-Longford. ARCHITECT Testosterone. In: Division AD, editor. Ireland: Abbott Laboratories; 2006. p. 1-7.

20. AIDD-Longford. ARCHITECT Estradiol. In: Division AD, editor. Ireland: Abbott Laboratories; 2009. p. 1-8.

21. Greenspan SL, Coates P, Sereika SM, Nelson JB, Trump $\mathrm{DL}$, Resnick NM. Bone loss after initiation of androgen deprivation therapy in patients with prostate cancer. $\mathrm{J}$ Clin Endocr Metab. 2005;90:6410-7.

22. Morote J, M'hammed YID, Martinez E, Esquena S, Lorente JA, Gelabert A. Increase of bone alkaline phosphatase after androgen deprivation therapy in patients with prostate cancer. Urology. 2002;59:27780.

\title{
PREVIOUS RELATED STUDY
}

H A Mwakyoma, J L MAGANDI. PROSTATE CANCER; CORRELATION OF GLEASON'S SCORE AND PRETREATMENT PROSTATE ANTIGEN IN PATIENTS (Original) Prof Med Jour 17(2) 235-240 Apr, May, Jun 2010.

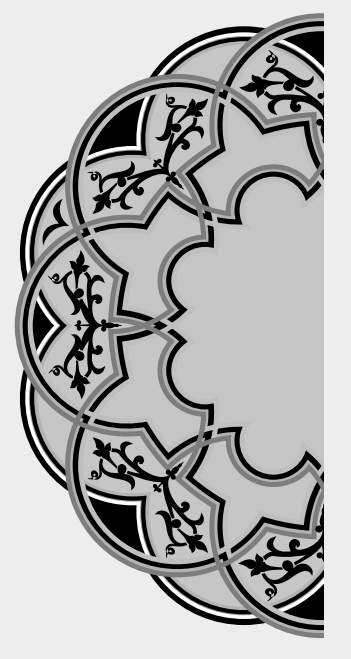

\section{"You are what you do, not what you say you'll do."}

\author{
Unknown
}

\section{AUTHORSHIP AND CONTRIBUTION DECLARATION}

\begin{abstract}
Sr. \#
Author-s Full Name

1 Dr. Syed Imran Ali Shah
\end{abstract}

2
Contribution to the paper

Concept, Design, Execution, Data collection, Analysis, Manuscript writing, Review, Final Approval

Concept, Design, Manuscript review, Final Approval
Author $=$ s Signature

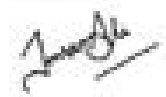

Moule 